Brit. Heart F., 1967, 29, 490.

\title{
Right Ventricular Systolic Pressure Gradients in Aortic Valve Disease
}

\author{
E. J. EPSTEIN, N. G. DOUKAS, N. COULSHED, AND A. K, BROWN \\ From Liverpool Regional Cardiac Centre, Sefton General Hospital, Liverpool 15
}

Obstruction to ventricular outflow may be either discrete and fixed, or dynamic and variable. A fixed obstruction is most common at valvar level but occasionally it may be subvalvar or supravalvar. Dynamic or functional obstruction is associated with hypertrophy of ventricular muscle and is invariably subvalvar.

This latter type of functional obstruction was first recognized in the right ventricle where subvalvar muscle hypertrophy developed as a result of severe pulmonary valve stenosis. Surgical treatment of the valvar lesion unmasked the subvalvar obstruction (Kirklin et al., 1953; Brock, 1955; Rodbard and Shaffer, 1956). A similar type of muscular obstruction was later recognized in the left ventricle by Brock (1957). Dynamic obstruction to left ventricular outflow due to an unknown disorder of cardiac muscle has been reported by many authors and variously called obstructive cardiomyopathy (Goodwin et al., 1960), muscular subaortic stenosis (Brent et al., 1960), or idiopathic hypertrophic subaortic stenosis (Braunwald et al., 1960).

Pressure gradients between the right ventricle and the pulmonary artery have been noted in association with left ventricular obstructive cardiomyopathy (Braunwald et al., 1964; Cohen et al., 1964) and in idiopathic combined ventricular hypertrophy without demonstrable left ventricular outflow obstruction (Taylor, Bernstein, and Jose, 1964; Braunwald et al., 1964).

We occasionally found systolic pressure gradients between the right ventricle and pulmonary artery in patients with aortic valve disease, and this observation suggested that it would be worth while to investigate the nature and site of this obstruction. The purpose of this paper is to show that severe left ventricular disease may produce secondary effects

Received July 26, 1966. on right ventricular function, and that systolic pressure gradients, which are dynamic in behaviour, may develop within the right ventricular cavity.

\section{Patients and Methods}

Studies were made on 16 patients with aortic valve disease, and they are subdivided as follows. Severe aortic stenosis: 10 patients; severe aortic stenosis with moderate aortic incompetence: 2 patients; severe aortic incompetence with moderate aortic stenosis: 1 patient; severe aortic incompetence: 3 patients.

Special studies were made at the time of routine diagnostic investigation.

Right heart catheterization was performed via the right saphenous vein and the catheter placed in the main pulmonary artery. A second N.I.H. type of catheter was then inserted and carefully positioned at the apex of the right ventricle. Left ventricular catheterization was performed by transseptal puncture of the atrial septum and a second catheter was inserted percutaneously into the femoral artery and positioned above the aortic valve.

In 13 patients simultaneous pressures were recorded from the right ventricle and pulmonary artery in partial expiration, using equisensitive induction manometers and a multichannel oscilloscopic recorder (Cambridge Instrument Company). The zero baselines were set at $5 \mathrm{~cm}$. below the sternal angle. In 12 patients tracings were also recorded continuously from the apex of the right ventricle as the second catheter in the pulmonary artery was withdrawn successively into the right ventricle and the right atrium (Fig. 1). In 3 patients only one catheter was inserted, and tracings were recorded in rapid succession from the pulmonary artery and right ventricle.

The effects of slow deep respiration were studied in 9 patients and of quiet respiration in 2 patients during simultaneous recording of right ventricular and pulmonary artery pressures.

The responses to the Valsalva manœuvre were re490 

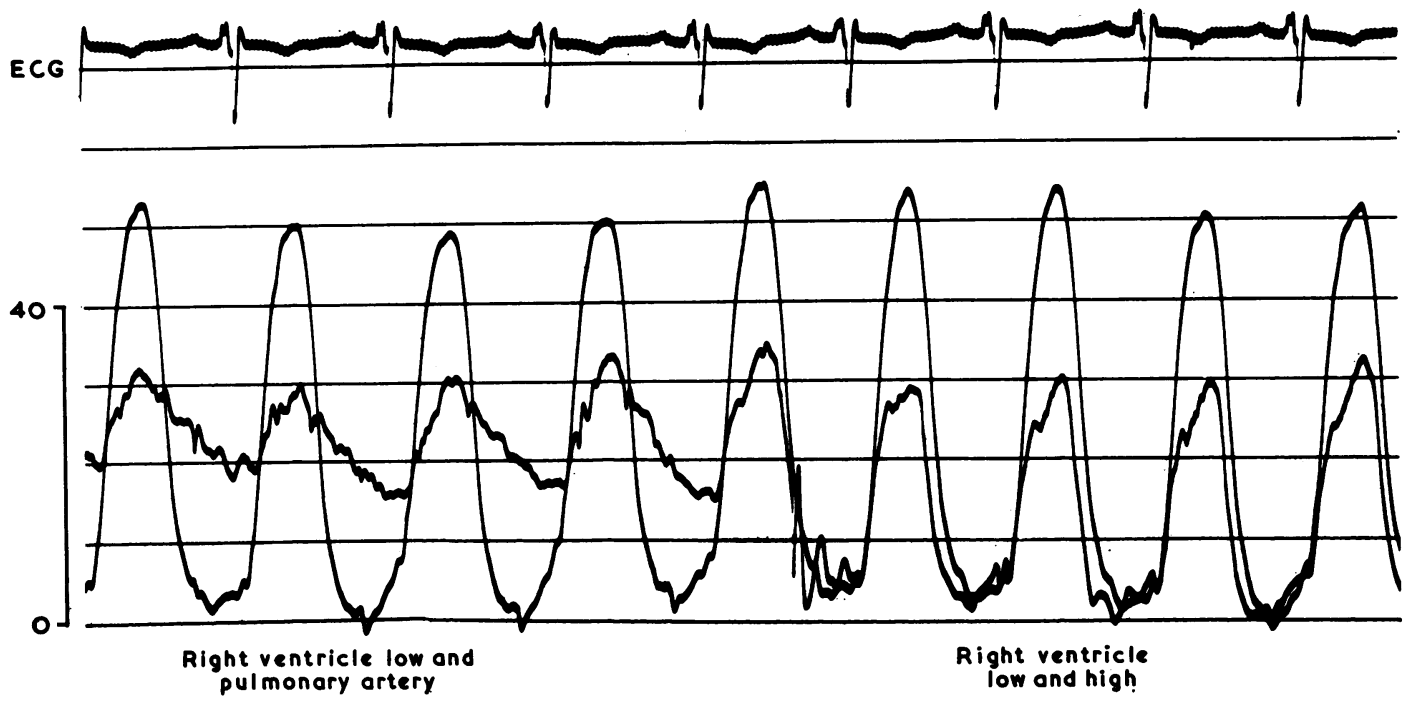

FIG, 1.-Patient No. 11 (J.R.). Pressure is continuously recorded from the apex of the right ventricle while another catheter is withdrawn from the pulmonary artery into the main body of the right ventricle. There is a peak systolic gradient of $20 \mathrm{~mm}$. Hg. The angiogram from this patient is shown in Fig. 8. The gradient lies between the apex and the main cavity of the ventricle and not at the level of the narrowed outflow tract. The pulmonary artery pulse wave is anacrotic and does not show the bifid wave form found in other patients.

with simultaneous tracings of either left ventricular and aortic pressures or of right ventricular and pulmonary artery pressures. In 8 patients the Valsalva manœuvre was performed on both the left and right sides. In one, only the left-sided Valsalva was studied, and in 2 only that on the right side.

The influence of post-ectopic beats on the gradient between the right ventricle and pulmonary artery and on the pulmonary arterial pulse pressure was observed in 12 patients.

The effect of isoprenaline infusion on the gradient between the right ventricle and pulmonary artery was measured in 2 patients. Cardiac outputs were measured by the Fick principle in the basal state and again during the isoprenaline infusion when its effects had stabilized. The effective right ventricular outflow orifice areas were calculated by the method of Gorlin and Gorlin (1951).

The effects of amyl nitrite inhalation on the gradient between the right ventricle and pulmonary artery were studied in 2 patients.

Biplane right ventricular angiocardiograms were obtained in 6 patients, using Elema-Schönander equipment with four exposures per second in each plane.

In addition studies were made on 3 other patients: one with coarctation of the aorta; one with coronary disease and left ventricular failure; and one with severe essential hypertension. Simultaneous pressures were recorded from the right ventricle and pulmonary artery during the Valsalva mancuvre and deep respiration. The effects of amyl nitrite inhalation were also studied in the patient with essential hypertension.

\section{RESULTS}

Hamodynamics in Basal State. The basal hæmodynamic data are set out in Table I. The systolic pressures at the right ventricular apex ranged from 29 to $75 \mathrm{~mm}$. $\mathrm{Hg}$ (average $47 \mathrm{~mm}$. $\mathrm{Hg}$ ) and the pulmonary artery systolic pressures from 18 to 45 $\mathrm{mm}$. $\mathrm{Hg}$ (average $28 \mathrm{~mm}$. $\mathrm{Hg}$ ). The peak systolic pressure gradients ranged from 8 to $46 \mathrm{~mm}$. $\mathrm{Hg}$ (average $19 \mathrm{~mm}$. $\mathrm{Hg}$ ). In 7 patients the right ventricular end-diastolic pressure at the apex exceeded $7 \mathrm{~mm}$. $\mathrm{Hg}$.

The ascending limb of the pressure pulse recorded at the apex of the right ventricle was often interrupted by a notch followed by slower rate of rise in pressure (Fig. 2 and 3). The pressure at the time of the notch was greater than the peak systolic pulmonary artery pressure. The systolic wave form in the pulmonary artery sometimes showed an early systolic peak followed by a mid-systolic dip and a smaller late secondary systolic wave (Fig. 2). A few patients failed to show this abnormality despite the presence of a significant systolic pressure gradient.

The peak systolic gradient between the left ventricle and aorta in the 12 patients with aortic stenosis ranged from 45 to $145 \mathrm{~mm}$. $\mathrm{Hg}$ (average $100 \mathrm{~mm}$. $\mathrm{Hg}$ ). In 8 patients the left ventricular end-diastolic pressure was more than $12 \mathrm{~mm}$. $\mathrm{Hg}$. 
TABLE I

BASAL HAMODYNAMIC DATA

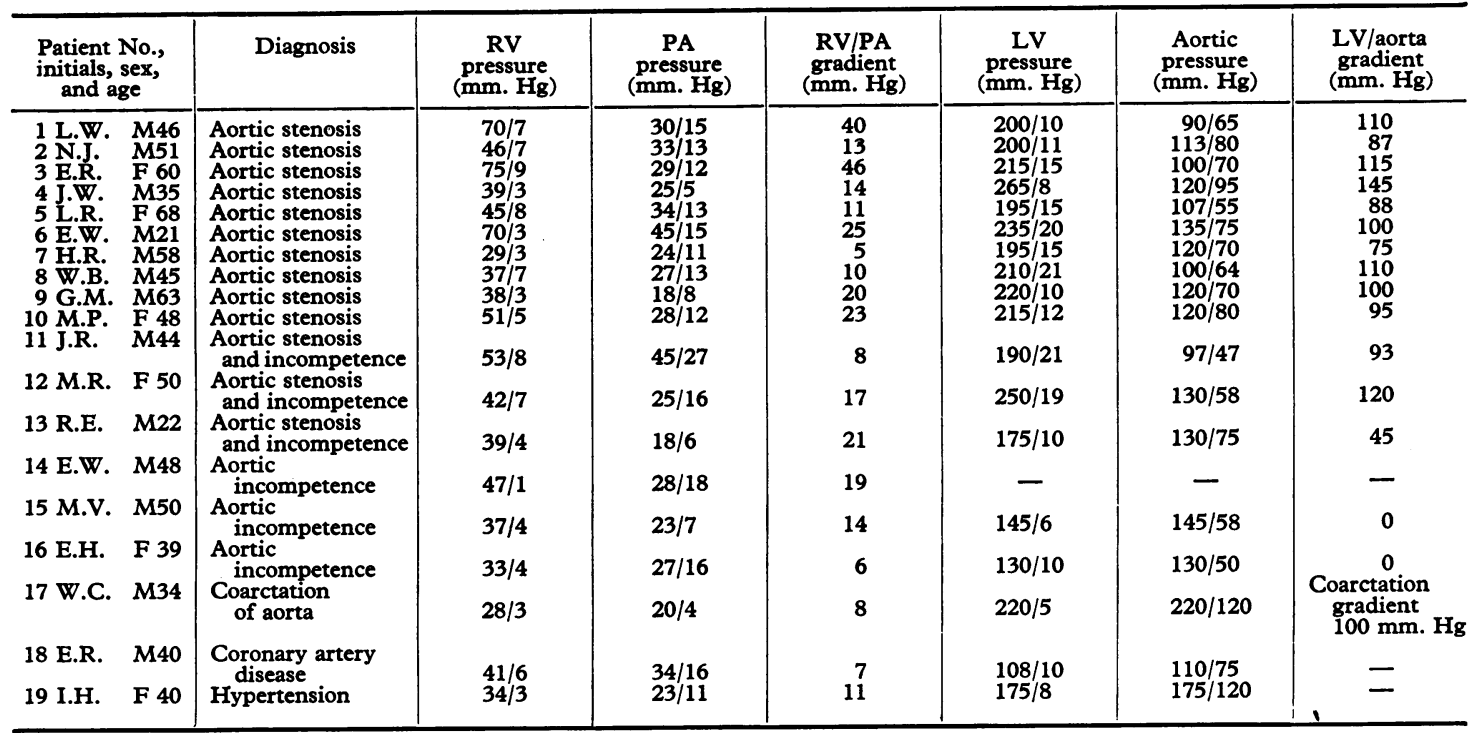

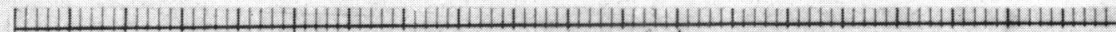
ECG
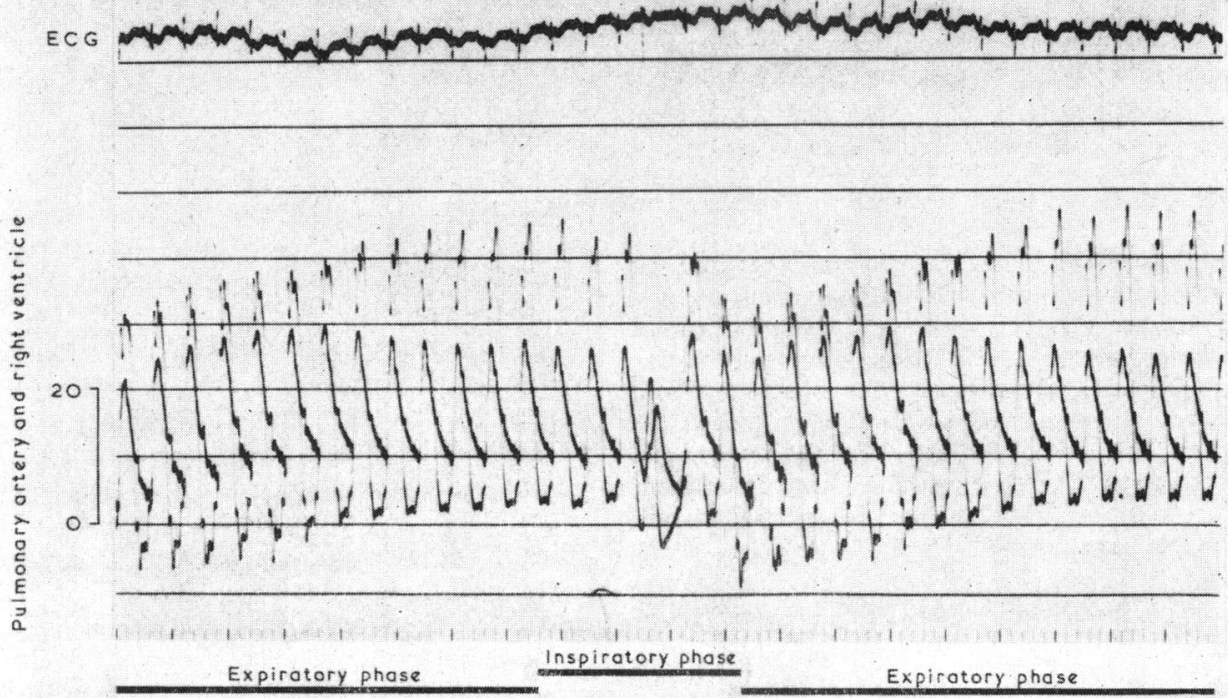

FIg. 2.-Patient No. 5 (L.R.). Simultaneous records from the right ventricle and pulmonary artery. Pressures in millimetres of mercury. Paper speed $15 \mathrm{~mm}$. per second. Maximal gradient of $17 \mathrm{~mm}$. $\mathrm{Hg}$ at the end of deep expiration. It falls to $5 \mathrm{~mm}$. $\mathrm{Hg}$ on deep inspiration. An ectopic beat is visible during inspiration with a negative post-ectopic phenomenon, i.e. increased arterial pulse pressure of the post-ectopic beat. The notch on the ascending limb of the right ventricular pressure pulse becomes more prominent in expiration, and the pulmonary artery pulse form shows an early systolic peak and a secondary smaller late systolic wave. 


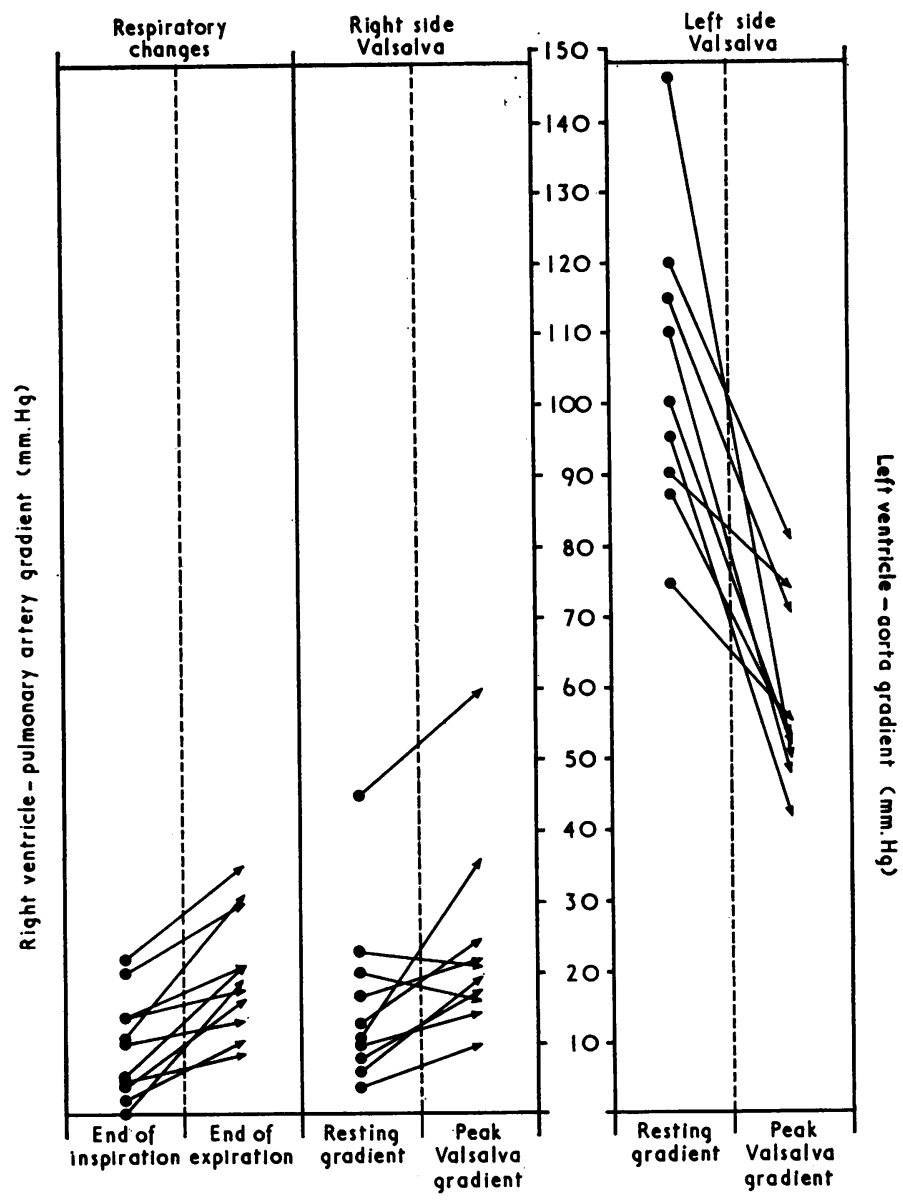

FIG. 3.-This shows the effects of respiration on the right-sided gradients and of the Valsalva manœuvre on both the left- and right-sided gradients. The average right-sided gradient was $11 \mathrm{~mm}$. $\mathrm{Hg}$, on deep inspiration and increased to $22 \mathrm{~mm}$. $\mathrm{Hg}$, on deep expiration. The right-sided gradient increased from an average of $17 \mathrm{~mm}$. $\mathrm{Hg}$ at rest, to $25 \mathrm{~mm}$. Hg at peak Valsalva. The left-sided gradient decreased from an average of $106 \mathrm{~mm}$. $\mathrm{Hg}$ at rest, to $58 \mathrm{~mm} . \mathrm{Hg}$ at peak Valsalva.

Respiratory Variations. The effects of respiration on the gradient between the right ventricle and the pulmonary artery in 11 patients are given in Table II and a typical example is shown in Fig. 2. The gradient at maximum inspiration ranged from 0 to $22 \mathrm{~mm}$. $\mathrm{Hg}$ (average $11 \mathrm{~mm} . \mathrm{Hg}$ ) and at maximum expiration from 9 to $35 \mathrm{~mm}$. $\mathrm{Hg}$ (average $22 \mathrm{~mm}$. $\mathbf{H g})$. There was, therefore, an average difference in systolic gradient of $11 \mathrm{~mm} . \mathrm{Hg}$ between inspiration and expiration. The largest difference was $20 \mathrm{~mm}$. $\mathrm{Hg}$ in Patient No. 10 (M.P.).

There were slight changes in the pulmonary arterial pulse wave in that the anacrotic notch disappeared on expiration (with maximal gradient) and the wave form tended to become bifid with an early systolic peak and a smaller late secondary systolic wave (Fig. 2 and 7).

The right ventricular pressure pulse also showed respiratory changes. During expiration (with maximal gradient) the ascending limb was interrupted by a prominent notch which became much smaller or disappeared on inspiration (with minimal gradient). The rate of rise in pressure was slowed following the notch with a late systolic peak pressure which was most marked in expiration.

Valsalva Manouvre. The effects of the Valsalva manœuvre are given in Table II and examples are shown in Fig. 3 and 4.

Right-sided studies were made on 10 patients. 
TABLE II

HEMODYNAMIC DATA IN VALSALVA MANGUVRE

\begin{tabular}{|c|c|c|c|c|c|c|c|}
\hline \multirow{2}{*}{$\begin{array}{l}\text { Patient } \\
\text { No. and } \\
\text { initials }\end{array}$} & \multirow[t]{2}{*}{ Diagnosis } & \multicolumn{2}{|c|}{ Respiratory changes } & \multicolumn{2}{|c|}{ Right-sided Valsalva } & \multicolumn{2}{|c|}{ Left-sided Valsalva } \\
\hline & & $\begin{array}{c}\text { End inspir. } \\
\text { RV/PA } \\
\text { gradient } \\
\text { (mm. Hg) }\end{array}$ & $\begin{array}{c}\text { End expir. } \\
\text { RV/PA } \\
\text { gradient } \\
\text { (mm. Hg) }\end{array}$ & $\begin{array}{l}\text { Resting } \\
\text { RV/PA } \\
\text { gradient } \\
\text { (mm. Hg) }\end{array}$ & $\begin{array}{c}\text { Peak } \\
\text { Valsalva } \\
\text { RV/PA } \\
\text { gradient } \\
\text { (mm. Hg) }\end{array}$ & $\begin{array}{l}\text { Resting } \\
\text { LV/aorta } \\
\text { gradient } \\
\text { (mm. Hg) }\end{array}$ & $\begin{array}{c}\text { Peak } \\
\text { Valsalva } \\
\text { LV/aorta } \\
\text { gradient } \\
(\mathrm{mm} . \mathrm{Hg})\end{array}$ \\
\hline $\begin{array}{l}2 \text { N.J. } \\
3 \text { E.R. } \\
4 \text { J.W. } \\
5 \text { L.R. } \\
7 \text { H.R. } \\
8 \text { W.B. } \\
9 \text { G.M. } \\
10 \text { M.P. } \\
11 \text { J.R. } \\
12 \text { M.R. } \\
14 \text { E.W. } \\
16 \text { E.H. } \\
17 \text { W.C. } \\
18 \text { E.R. } \\
19 \text { I.H. }\end{array}$ & $\begin{array}{l}\text { Aortic stenosis } \\
\text { Aortic stenosis } \\
\text { Aortic stenosis } \\
\text { Aortic stenosis } \\
\text { Aortic stenosis } \\
\text { Aortic stenosis } \\
\text { Aortic stenosis } \\
\text { Aortic stenosis } \\
\text { Aortic stenosis and incompetence } \\
\text { Aortic stenosis and incompetence } \\
\text { Aortic incompetence } \\
\text { Aortic incompetence } \\
\text { Coarctation } \\
\text { Coronary artery disease } \\
\text { Hypertension }\end{array}$ & $\begin{array}{r}10 \\
22 \\
0 \\
4 \\
5 \\
14 \\
11 \\
14 \\
20 \\
5 \\
2 \\
3 \\
1 \\
5\end{array}$ & $\begin{array}{r}14 \\
35 \\
19 \\
17 \\
9 \\
21 \\
31 \\
18 \\
30 \\
21 \\
11 \\
16 \\
18 \\
11\end{array}$ & $\begin{array}{r}13 \\
46 \\
11 \\
5 \\
10 \\
20 \\
23 \\
8 \\
17 \\
6 \\
8 \\
7 \\
10\end{array}$ & $\begin{array}{l}25 \\
\frac{60}{36} \\
10 \\
15 \\
16 \\
21 \\
18 \\
22 \\
20 \\
19 \\
15 \\
12\end{array}$ & $\begin{array}{r}87 \\
115 \\
145 \\
88 \\
\overline{110} \\
100 \\
95 \\
93 \\
120 \\
= \\
= \\
=\end{array}$ & $\begin{array}{l}53 \\
70 \\
50 \\
55 \\
48 \\
52 \\
42 \\
73 \\
80 \\
- \\
- \\
- \\
-\end{array}$ \\
\hline
\end{tabular}

In 8, there was some increase in the gradient between the right ventricle and the pulmonary artery during the straining period. In one the gradient was unchanged and in another there was a slight fall in gradient.

The resting gradients ranged from 5 to $46 \mathrm{~mm}$.
$\mathrm{Hg}$ (average $17 \mathrm{~mm} . \mathrm{Hg}$ ), and during the Valsalva manœuvre the gradients ranged from 10 to 60 $\mathrm{mm}$. $\mathrm{Hg}$ (average $25 \mathrm{~mm}$. $\mathrm{Hg}$ ). Therefore, on average the systolic gradient increased by $8 \mathrm{~mm}$. $\mathrm{Hg}$. The Valsalva manœuvre produced a fall in both right ventricular and pulmonary artery pressures,

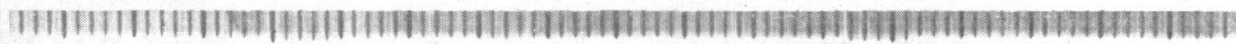

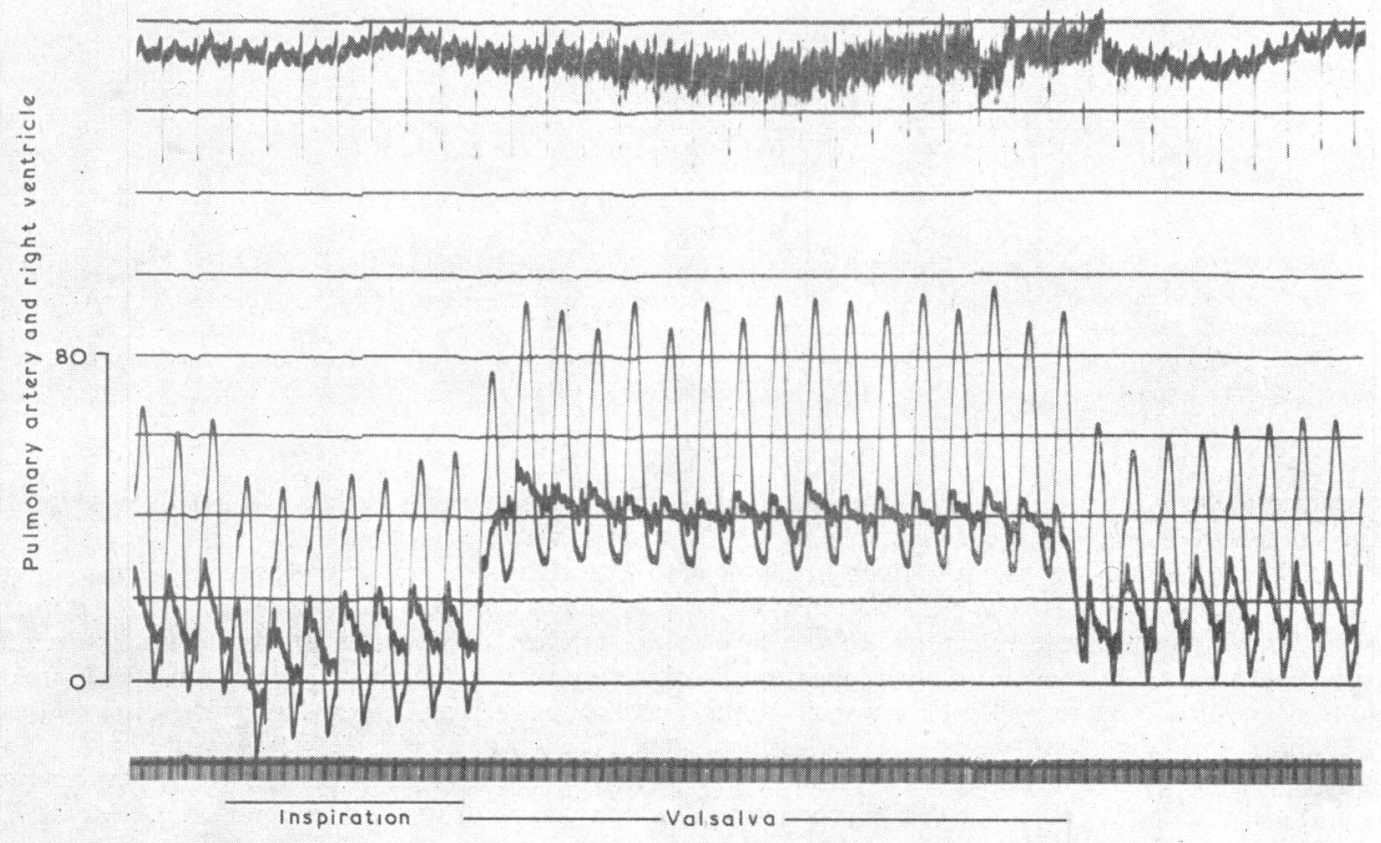

Fig. 4.-Patient No. 3 (E.R.). The effects of the Valsalva manœuvre on simultaneous pressures recorded in the right ventricle and pulmonary artery. There is an increase in gradient from $40 \mathrm{~mm}$. $\mathrm{Hg}$, at rest, to 55 $\mathrm{mm}$. $\mathrm{Hg}$, during the Valsalva manœuvre. The gradient falls again following release of the Valsalva. The pulmonary artery pulse pressure falls during the strain, and an early systolic peak appears followed by a mid-systolic dip and a late smaller secondary systolic peak. The right ventricular pressure does not alter. 


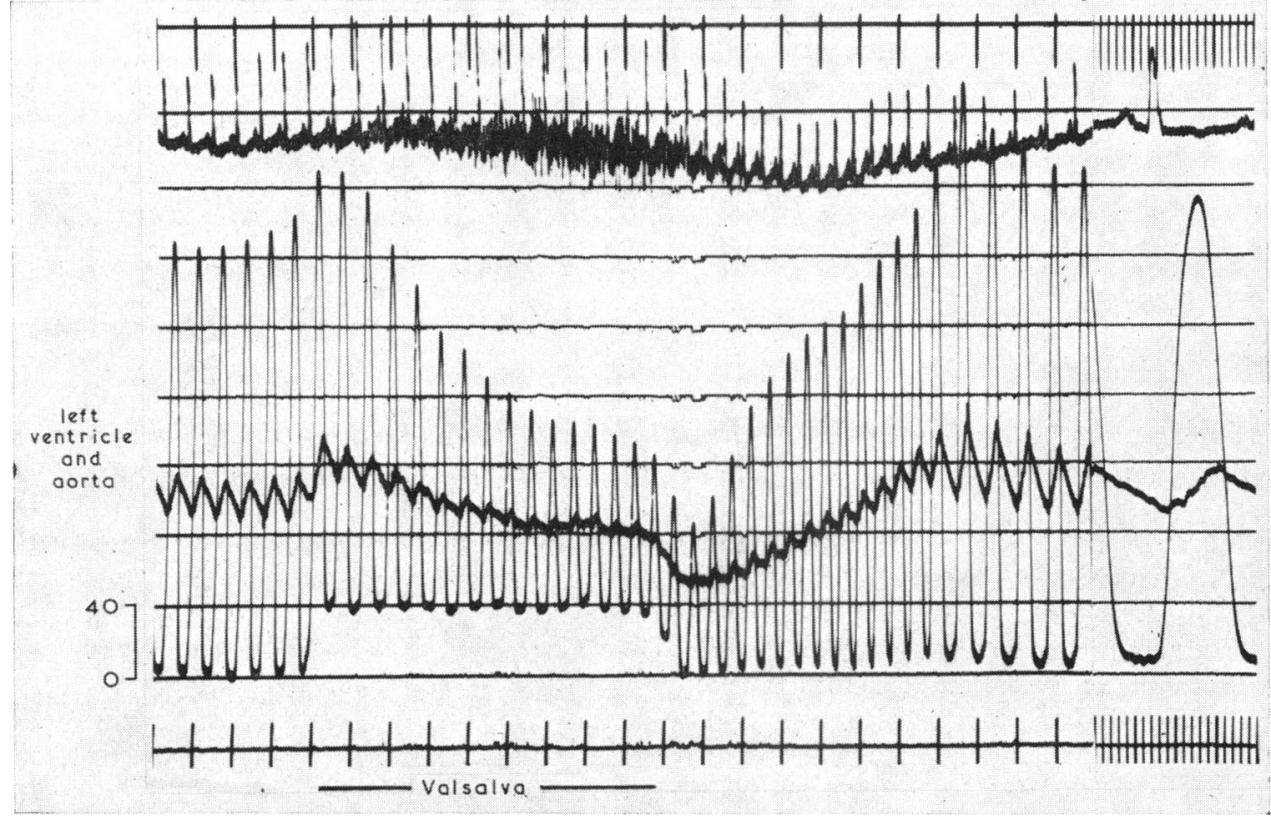

Fig. 5.-Patient No. 4 (J.W.). The effects of the Valsalva manœuvre on simultaneous pressure records from the left ventricle and aorta. The resting gradient of $140 \mathrm{~mm} . \mathrm{Hg}$ falls to $50 \mathrm{~mm} . \mathrm{Hg}$ during the straining period. Following release of the Valsalva there is a gradual return to the resting level. A single complex at fast paper speed is shown on the right of the tracing to illustrate the pulse contours.

which was proportionally greater in the pulmonary artery. The pressure tracings from the pulmonary artery tended to alter in contour during the strain. An early systolic peak appeared, or if present it became more prominent, and was followed by a midsystolic dip which was in turn followed by a late smaller secondary systolic peak (Fig. 4).

Left-sided studies were made in 8 of the above 10 patients and also in one additional patient. All of the 9 studied showed a fall in the systolic gradient between the left ventricle and the aorta during the straining period (Fig. 5). The resting gradients ranged from 88 to $145 \mathrm{~mm}$. $\mathrm{Hg}$ (average $106 \mathrm{~mm}$. $\mathrm{Hg}$ ), and during the Valsalva manœuvre the gradients ranged from 42 to $80 \mathrm{~mm}$. $\mathrm{Hg}$ (average 58 $\mathrm{mm}$. $\mathrm{Hg}$ ). Therefore, on average the systolic gradient fell by $48 \mathrm{~mm}$. Hg.

Post-ectopic Phenomenon. Studies were made in 12 patients on the effects of an ectopic beat on the succeeding right ventricular and pulmonary artery pressure pulses, as described by Brockenbrough, Braunwald, and Morrow (1961) on the left side in cardiomyopathy. Normally the arterial pulse pressure of the post-ectopic beat is increased. When the phenomenon is positive the response is paradoxical and the post-ectopic arterial pulse pressure is diminished. In all 12 patients the response was negative in that the post-ectopic beat showed an increase in both the pulse pressure and the systolic pressure in the pulmonary artery as well as a rise in right ventricular pressure and in the systolic gradient (Fig. 2).

Isoprenaline Infusion. The effects of isoprenaline infusion on right-sided hæmodynamics were studied in two patients (J.W. and W.B.) and the results are given in Table III and Fig. 6 . In the first patient (J.W.) the right ventricular pressure increased from $39 / 1$ to $60 / 2 \mathrm{~mm}$. $\mathrm{Hg}$ following isoprenaline and the peak systolic gradient rose from 14 to $30 \mathrm{~mm}$. Hg. The cardiac output showed no significant change, and the calculated effective right ventricular outflow orifice decreased from 1.24 $\mathrm{cm}^{2}$ to $0.84 \mathrm{~cm}{ }^{2}$ The pulmonary artery pressure increased by only $5 \mathrm{~mm}$. $\mathrm{Hg}$, but the pulse form now showed an early systolic peak followed by a trough and a secondary rise in systolic pressure. In the second patient (W.B.) isoprenaline produced an increase in right ventricular pressure from $27 / 5$ to $36 / 8 \mathrm{~mm}$. $\mathrm{Hg}$ and in pulmonary arterial pressure from $22 / 8$ to $28 / 12 \mathrm{~mm}$. Hg. The systolic gradient increased from 5 to $8 \mathrm{~mm}$. Hg. The calculated effective right ventricular outflow orifice showed 
TABLE III

EFFECTS OF ISOPRENALINE INFUSION

\begin{tabular}{|c|c|c|c|c|c|c|c|c|c|}
\hline Patient No. & Diagnosis & & $\begin{array}{c}\text { Heart rate } \\
\text { (beats/ } \\
\text { min.) }\end{array}$ & $\begin{array}{c}\text { RV systolic } \\
\text { pressure } \\
(\mathbf{m m} . \mathbf{H g})\end{array}$ & $\begin{array}{l}\text { RV end- } \\
\text { diastolic } \\
(\mathbf{m m} . \mathbf{H g})\end{array}$ & $\begin{array}{c}\text { PA systolic } \\
\text { pressure } \\
(\mathbf{m m} . \mathbf{H g})\end{array}$ & $\begin{array}{c}\text { Peak RV/ } \\
\text { PA gradient } \\
\text { (mm. Hg) }\end{array}$ & $\begin{array}{l}\text { Cardiac } \\
\text { output } \\
(1 . / \mathrm{min} .)\end{array}$ & $\begin{array}{l}\text { RV outflow } \\
\text { orifice } \\
\text { (cm. }\end{array}$ \\
\hline 4 & $\begin{array}{l}\text { Aortic } \\
\text { stenosis }\end{array}$ & $\left\{\begin{array}{l}\text { Control } \\
\text { Isoprenaline }\end{array}\right.$ & $\begin{array}{l}92 \\
94\end{array}$ & $\begin{array}{l}39 \\
60\end{array}$ & $\begin{array}{l}1 \\
2\end{array}$ & $\begin{array}{l}25 \\
30\end{array}$ & $\begin{array}{l}14 \\
30\end{array}$ & $\begin{array}{l}5 \cdot 9 \\
5 \cdot 4\end{array}$ & $\begin{array}{l}1 \cdot 23 \\
0 \cdot 84\end{array}$ \\
\hline 8 & $\begin{array}{l}\text { Aortic } \\
\text { stenosis }\end{array}$ & $\left\{\begin{array}{l}\text { Control } \\
\text { Isoprenaline }\end{array}\right.$ & $\begin{array}{l}79 \\
77\end{array}$ & $\begin{array}{l}27 \\
36\end{array}$ & $\begin{array}{l}5 \\
8\end{array}$ & $\begin{array}{l}22 \\
28\end{array}$ & $\begin{array}{l}5 \\
8\end{array}$ & $\begin{array}{l}6 \cdot 8 \\
8 \cdot 8\end{array}$ & $\begin{array}{l}3 \cdot 0 \\
3 \cdot 25\end{array}$ \\
\hline
\end{tabular}

little change and was $3.0 \mathrm{~cm} .{ }^{2}$ before and $3.25 \mathrm{~cm} .{ }^{2}$ after isoprenaline (Table III).

Amyl Nitrite. The effects of amyl nitrite inhalation were studied in two patients (M.R. and E.H.) and the results are given in Table IV. In patient M.P., the gradient increased from $20 \mathrm{~mm}$. $\mathrm{Hg}$ at rest to $38 \mathrm{~mm}$. Hg two minutes after inhalation (Fig. 7). After five minutes the gradient had re- turned to the resting level. There was an associated rise in right ventricular systolic pressure from 43 to $70 \mathrm{~mm}$. Hg. The other patient, E.H., showed an increase in systolic gradient from 15 to $35 \mathrm{~mm}$. $\mathrm{Hg}$, two and a half minutes after inhalation, with a return to the basal level after five minutes.

Right Ventricular Angiography. Six patients had selective right ventricular biplane angiography.

Pulmonory ortery ond right ventricle
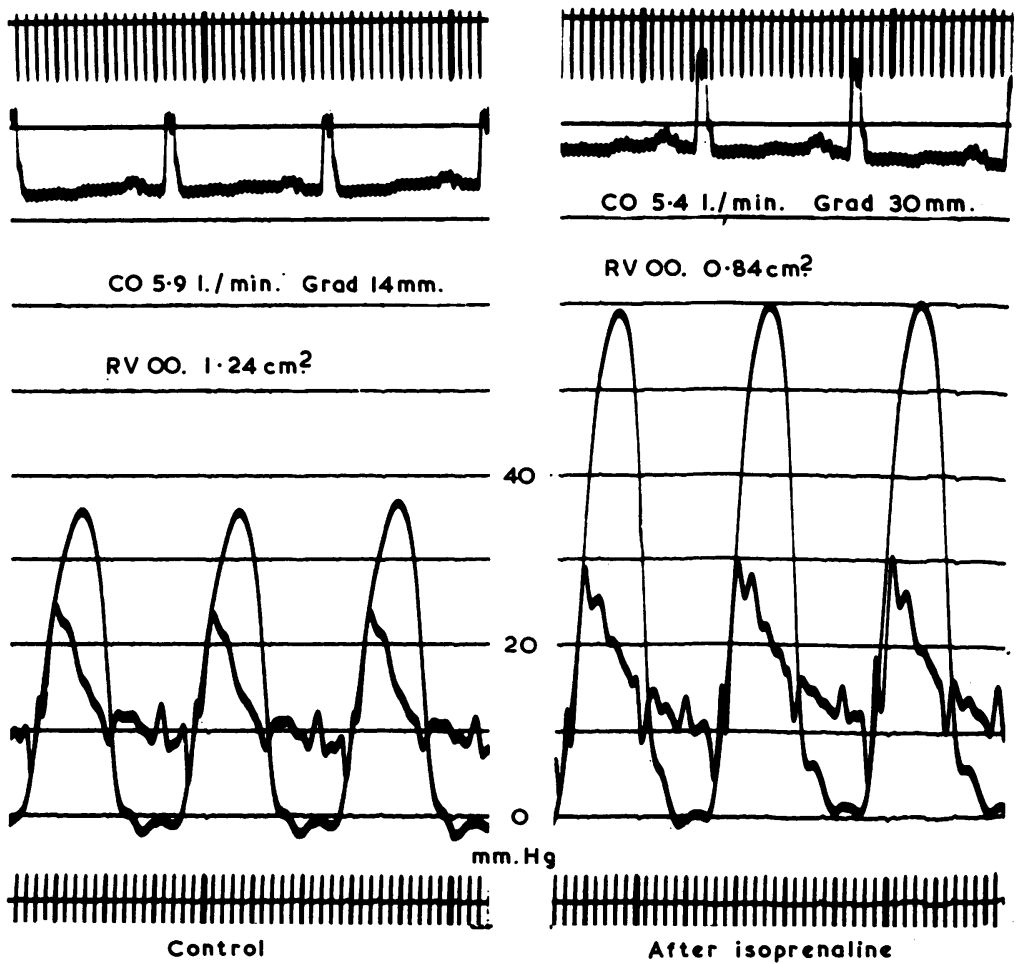

CO $5.41 .1 \mathrm{~min}$. Grad $30 \mathrm{~mm}$.

RV OO. $0.84 \mathrm{~cm}^{2}$ ?

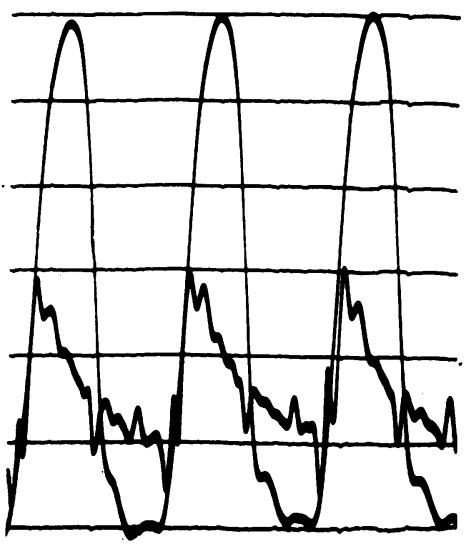

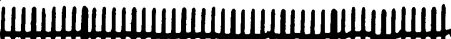

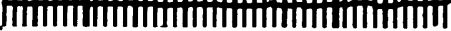

After isoprenaline

FIG. 6.-Patient No. 4 (J.W.). Effects of isoprenaline on the right-sided gradient in a patient with severe aortic stenosis. The peak systolic gradient between right ventricle and pulmonary artery increases from 14 to $30 \mathrm{~mm} . \mathrm{Hg}$, and the effective area of the right ventricular outflow orifice decreases from $1.24 \mathrm{~cm} .2$ to $0.84 \mathrm{~cm} .2$ ( $C O=$ cardiac output; $G R A D=$ peak systolic gradient; and $R V O O=$ right ventricular outflow orifice). 
TABLE IV

EFFECTS OF AMYL NITRITE INHALATION

\begin{tabular}{|c|c|c|c|c|c|c|c|c|}
\hline $\begin{array}{l}\text { Patient No., } \\
\text { initials, sex, } \\
\text { and age }\end{array}$ & Diagnosis & & $\begin{array}{c}\text { Heart rate } \\
\text { (beats / } \\
\text { min.) }\end{array}$ & $\begin{array}{c}\text { RV systolic } \\
\text { pressure } \\
\text { (mm. Hg) }\end{array}$ & $\begin{array}{l}\text { RV end- } \\
\text { diastolic } \\
\text { pressure } \\
\text { (mm. Hg) }\end{array}$ & $\begin{array}{c}\text { PA systolic } \\
\text { pressure } \\
(\mathrm{mm} . \mathbf{H g})\end{array}$ & $\begin{array}{c}\text { PA diastolic } \\
\text { pressure } \\
(\mathbf{m m} . \mathbf{H g})\end{array}$ & $\begin{array}{c}\text { Peak RViPA } \\
\text { gradient } \\
\text { (mm. Hg) }\end{array}$ \\
\hline 10 M.P. F 48 & $\begin{array}{l}\text { Aortic } \\
\text { stenosis }\end{array}$ & $\left\{\begin{array}{l}\text { Control } \\
\text { Peak Effect } \\
(120 \mathrm{sec} .)\end{array}\right.$ & $\begin{array}{r}99 \\
135\end{array}$ & $\begin{array}{l}43 \\
69\end{array}$ & $\begin{array}{l}6 \\
6\end{array}$ & $\begin{array}{l}23 \\
31\end{array}$ & $\begin{array}{l}11 \\
12\end{array}$ & $\begin{array}{l}20 \\
38\end{array}$ \\
\hline 16 E.H. F 39 & $\begin{array}{l}\text { Aortic } \\
\text { incompetence }\end{array}$ & $\left\{\begin{array}{l}\text { Control } \\
\text { Peak Effect } \\
(60 \mathrm{sec} .)\end{array}\right.$ & $\begin{array}{r}94 \\
120\end{array}$ & $\begin{array}{l}33 \\
44\end{array}$ & $\begin{array}{l}4 \\
1\end{array}$ & $\begin{array}{l}25 \\
26\end{array}$ & $\begin{array}{l}13 \\
11\end{array}$ & $\begin{array}{r}8 \\
18\end{array}$ \\
\hline
\end{tabular}

In general the right ventricle was of small size, and there was bulging of the ventricular septum into the cavity with displacement and rotation to the right. In four patients there was excessive trabeculation, particularly of the septal wall, and during systole the apex was almost completely obliterated so that the catheter tip appeared to be outside the opacified area of ventricular cavity at end-systole. The septal and parietal bands of the crista supraventricularis were hypertrophied in the six patients studied, and the infundibular area showed excessive systolic narrowing in three patients, as assessed by the index of Little, Lavender, and DeSanctis (1963) (Fig. 8).
The pulmonary valve was normal in all six patients. These angiograms closely resembled right ventricular angiograms in patients with obstructive cardiomyopathy.

\section{Discussion}

There is some difference of opinion as to the nature of the gradients between the right ventricle and pulmonary artery in patients with obstructive cardiomyopathy. Mason, Braunwald, and Ross (1965) and Lockhart et al. (1966) consider that the right ventricle is primarily involved by the cardio-
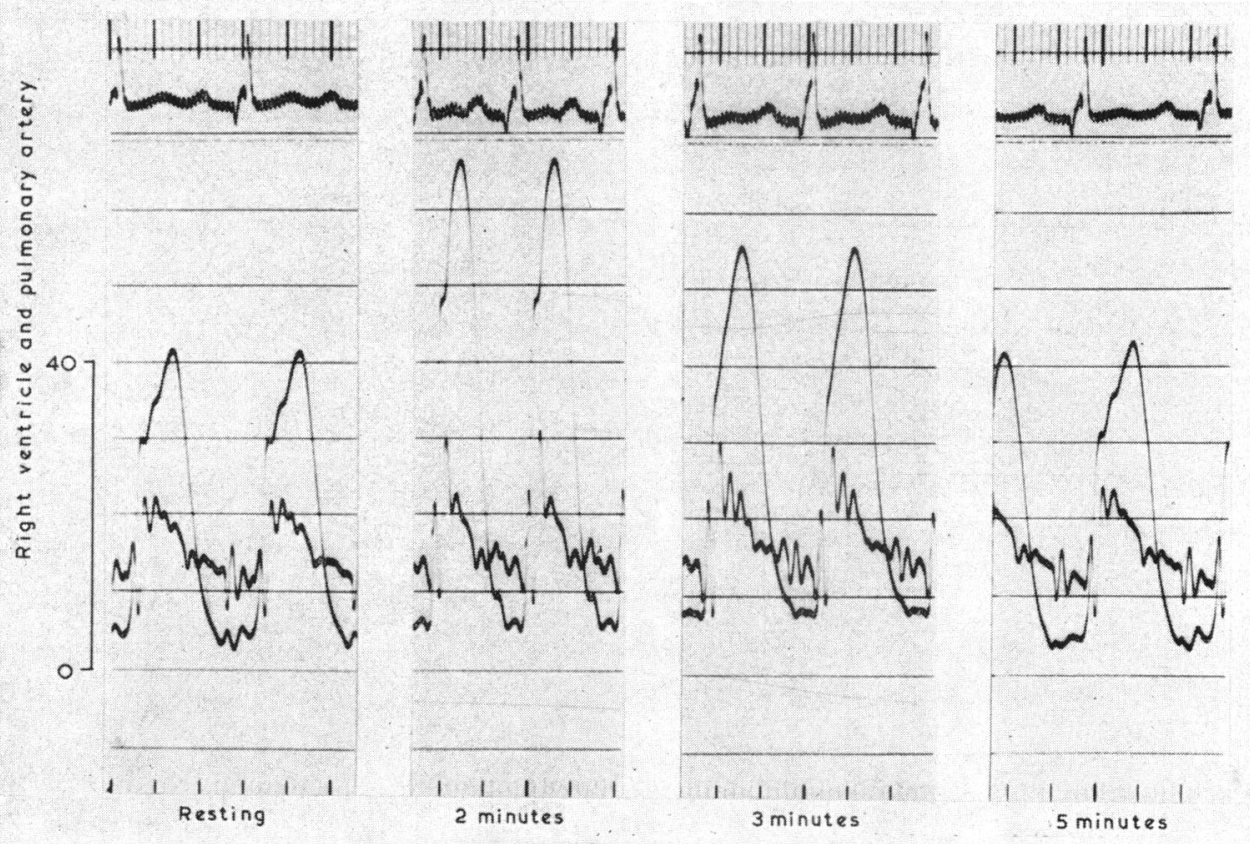

3 minutes

5 minutes

FIG. 7.-Patient No. 10 (M.P.). Effects of amyl nitrite inhalation on right-sided pressures in a patient with severe aortic stenosis. There is an increase in right ventricular systolic pressure from 42 to $67 \mathrm{~mm}$. $\mathrm{Hg}$, and in the peak systolic gradient from 20 to $38 \mathrm{~mm}$. $\mathrm{Hg}$. The pulmonary arterial pulse becomes more bifid, and there is a rise in right ventricular end-diastolic pressure. The pressures return to resting levels within five minutes. 


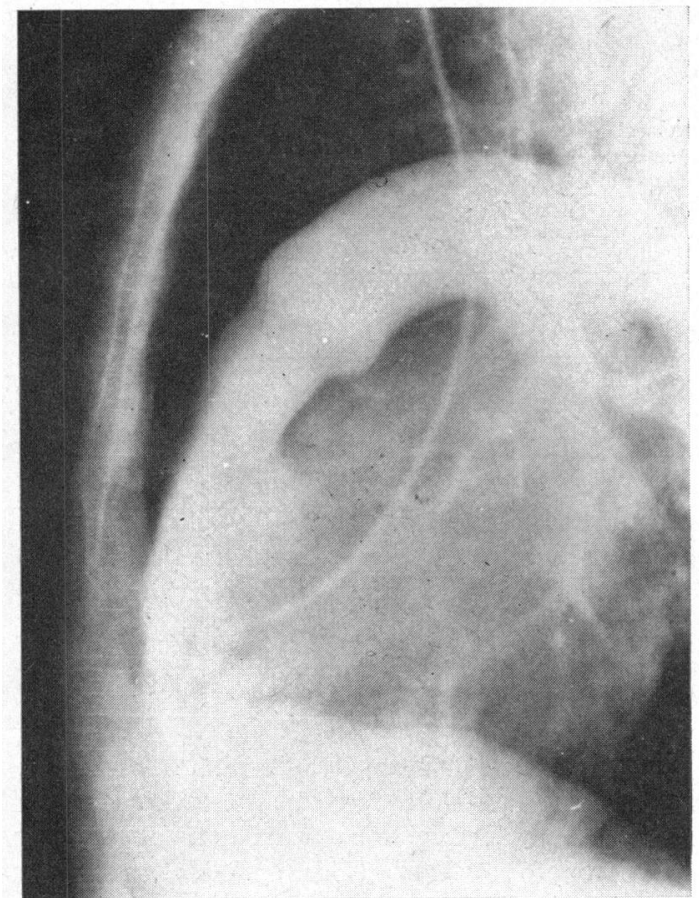

A

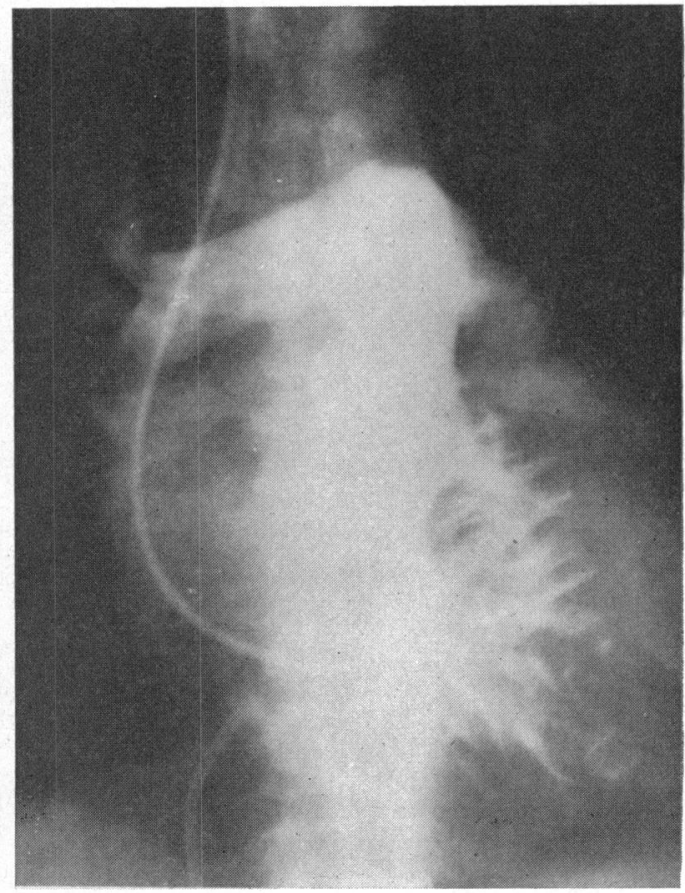

C

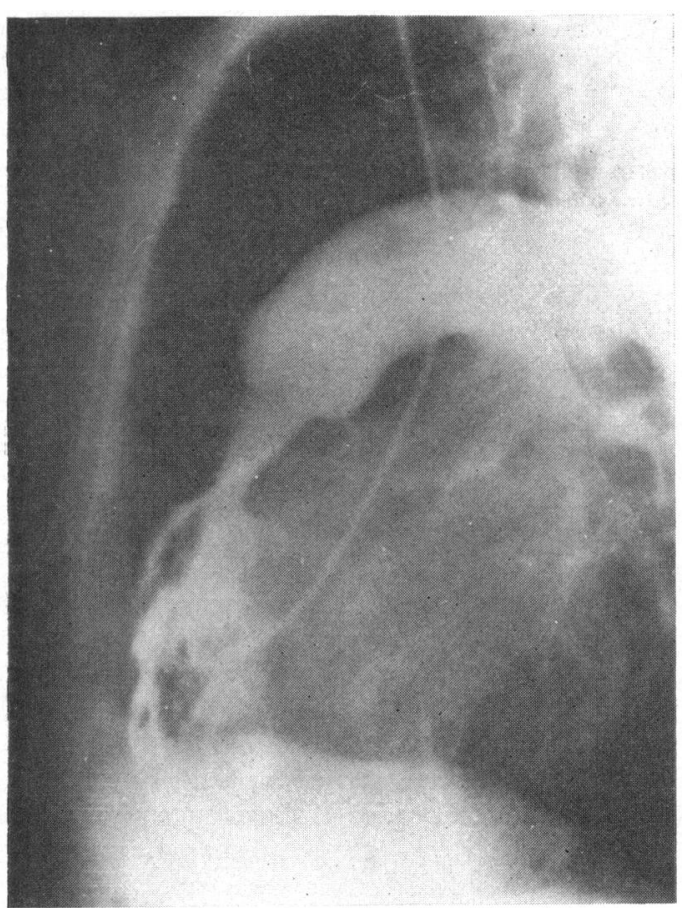

B

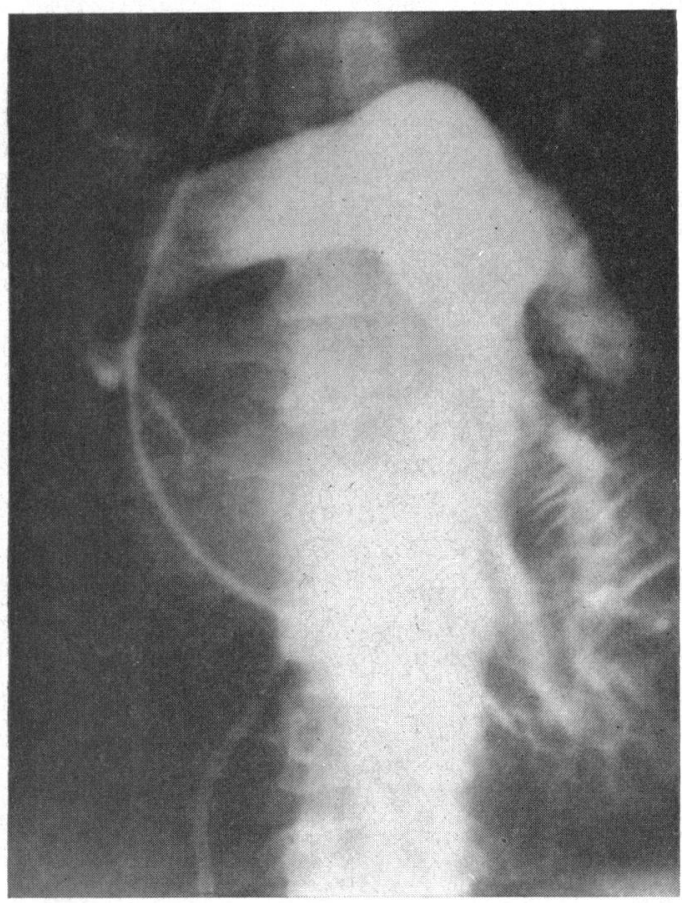

D

Frg. 8.-Patient No. 11 (J.R.). Right ventricular biplane angiogram. In the lateral view, $A=$ diastole; $\mathrm{B}=$ systole. In the antero-posterior view, $\mathrm{C}=$ diastole; $\mathrm{D}=$ systole. The outflow tract shows marked narrowing in systole due to hypertrophy of the septal and parietal bands of the crista supraventricularis. There is antero-posterior compression of the right ventricular cavity, with some displacement to the right and hypertrophy of the muscle bundles of the anterior wall and the septum. 
myopathy, and that disordered right ventricular contraction produces outflow obstruction. Goodwin et al. (1964), Oakley (1964), and Wigle (1964) believe that the gradient is secondary to the left ventricular disorder, due to bulging of the grossly hypertrophied septum into the right ventricular cavity, rather than a primary affection of the right ventricle by the cardiomyopathy.

Various physiological manœuvres such as the Valsalva manœuvre (Braunwald et al., 1964; Marcus and Jones, 1965) and deep respiration (Shah et al., 1965) can alter the left-sided gradient in hypertrophic obstructive cardiomyopathy. The Valsalva manœuvre increases intrathoracic pressure and results in a diminished venous return and a fall in stroke volume. In aortic valve stenosis there is a moderate fall in left ventricular systolic pressure, aortic systolic pressure, and in the systolic gradient during the straining period due to the reduced stroke volume (Fig. 5). Obstructive cardiomyopathy shows a different response to the Valsalva manouvre. The left ventricular systolic pressure remains unchanged or increases and the aortic systolic pressure falls. The systolic gradient between the left ventricle and the aorta, therefore, increases. This increase of gradient develops despite the fall in stroke volume. The end-systolic volume of the left ventricle is diminished during the Valsalva manœuvre, and it has been suggested that the outflow tract contracts down more completely and increases the outflow obstruction (Braunwald et al., 1964; Wigle et al., 1965; Marcus and Jones, 1965).

As far as we are aware, no studies have been published on the effects of the Valsalva manœuvre on the right side of the heart, though Braunwald $e t$ al. (1964) refer to one patient with idiopathic hypertrophic subaortic stenosis with a right-sided gradient which increased during the Valsalva manœuvre. Our own experience has shown that fixed orifice pulmonary stenosis behaves in a similar fashion to aortic valve stenosis, with a fall in the pulmonary systolic gradient during the Valsalva manœuvre. In addition, the right-sided systolic pressure gradient in obstructive cardiomyopathy behaves paradoxically, as does that on the left side, during the Valsalva manœuvre, and it either shows little change or it increases. The systolic pressure gradients between the right ventricle and the pulmonary artery in the series of patients reported here showed a Valsalva response similar to that of patients with obstructive cardiomyopathy (Fig. 3 and 4), thus demonstrating the dynamic nature of the gradient.

Shah et al. (1965) reported the effects of respiration on the systolic gradient between the left ventricle and the aorta in obstructive cardiomyopathy.
The gradient increased during expiration and fell during inspiration. They attributed these effects to changes in stroke volume, with a fall during expiration and hence maximal systolic emptying of the ventricle and increased obstruction to outflow. We have observed the opposite effect in fixed orifice aortic valve stenosis, in that the gradient increased during inspiration and decreased during expiration. The 11 patients studied in this report all had a cardiomyopathic type of response to respiration on the right side of the heart, in that inspiration diminished the gradient and expiration increased it (Fig. 2 and 3).

In normal people and in patients with valvar or discrete subvalvar aortic stenosis, the cardiac cycle following a premature contraction shows a more forceful ventricular contraction than a normal one and an arterial pulse pressure greater than the control. The left ventricular contraction in patients with obstructive cardiomyopathy shows a normal post-extrasystolic augmentation; however, the aortic pulse pressure fails to increase. It is thought that the increased force of myocardial contraction intensifies the outflow obstruction (Brockenbrough et al., 1961). Studies of right-sided obstructive cardiomyopathy have shown a normal rise in the pulmonary artery pulse pressure following the postectopic pause (Oakley, 1964; Lockhart et al., 1966), and this has also been our experience in patients with cardiomyopathy.

In all 12 patients studied in this series the postectopic phenomenon was negative. That is, after the post-ectopic pause the pulmonary arterial pulse pressure showed an increase rather than a fall. The reason for this response is not clear, but it has been suggested that in right-sided obstructive cardiomyopathy this negative response favours a secondary rather than a primary abnormality of the right ventricle (Oakley, 1964).

Pharmacological agents can alter the gradient between the left ventricle and aorta in hypertrophic obstructive cardiomyopathy (Braunwald and Ebert, 1962; Whalen et al., 1963; Krasnow et al., 1963). Isoprenaline can provoke or intensify left-sided pressure gradients by enhancing myocardial contractility. Goodwin et al. (1964) studied rightsided pressure gradients in obstructive cardiomyopathy and found only slight changes following infusion of isoprenaline. On the other hand, Mason et al. (1965) and Lockhart et al. (1966) found that isoprenaline in cardiomyopathy produced a moderate increase in the gradient between the right ventricle and pulmonary artery and reduced the calculated outflow orifice, thus demonstrating its dynamic nature.

One of our patients (J.W.) showed a dynamic 
response to infusion of isoprenaline, with an increase in the right ventricular systolic gradient and a reduction in the calculated outflow orifice (Table III and Fig. 6). The other patient (W.B.) showed no significant change in systolic gradient or effective outflow orifice. Our limited studies therefore show a variable type of response, and certainly in some patients with aortic valve disease isoprenaline may intensify the right ventricular obstruction.

Inhalation of amyl nitrite produces arteriolar and venous dilatation, with a fall in arterial systolic pressure, tachycardia, and an increased cardiac output. The stroke volume falls or remains unchanged (Beck et al., 1961). In aortic valve stenosis amyl nitrite produces a fall in both left ventricular and aortic pressures, with an increase in the systolic gradient. Although amyl nitrite increases the systolic gradient in left ventricular obstructive cardiomyopathy, this is accomplished by a fall in aortic systolic pressure while the left ventricular systolic pressure remains unchanged or increases (Wigle et al., 1963; Goodwin et al., 1964; Hancock and Fowkes, 1966). Goodwin et al. (1964) found no significant change in the systolic gradient on the right side in patients with obstructive cardiomyopathy following amyl nitrite inhalation. However, in four of our patients with obstructive cardiomyopathy, amyl nitrite produced an increase in the right ventricular systolic pressure and also in the systolic gradient between the right ventricle and the pulmonary artery. The two patients with aortic valve disease studied in this report responded in a similar manner to our four patients with rightsided obstructive cardiomyopathy, and showed an increase in both right ventricular systolic pressure and in the systolic gradient between the right ventricle and the pulmonary artery (Fig. 7).

The pressure gradient in the right ventricle which developed in Patient No. 14 (E.W.) is of some interest. This patient was in severe left ventricular failure when right ventricular and pulmonary artery pressures were first recorded and there was no systolic pressure gradient (Fig. 9). Thirty minutes later after treatment with oxygen, aminophylline, and venesection, the left ventricular failure had resolved. There was then a systolic gradient between the apex of the right ventricle and the pulmonary artery (Fig. 9). The right ventricular pressure had fallen slightly and the pulmonary artery pressure had fallen noticeably in association with a dramatic fall in left atrial mean pressure from 21 to $7 \mathrm{~mm}$. $\mathrm{Hg}$.

These findings suggest that the systolic pressure gradient in the right ventricle may be produced or abolished by lowering or raising pulmonary arterial pressure. This is analogous to the effects of raising or lowering systemic arterial pressure on the sys- tolic gradient in obstructive cardiomyopathy of the left ventricle. Wigle et al. (1965) have shown that systemic vasoconstriction abolished or decreased the gradient in muscular subaortic stenosis. They postulated that these effects were due to alterations in the systolic distending pressure in the left ventricular outflow tract.

Acute changes in left atrial pressure are associated with similar directional changes in pulmonary arterial pressure. If the pulmonary artery pressure is raised much, then the associated high right ventricular pressure might serve to counteract the bulging of the septum into its cavity and abolish any systolic pressure gradient. Cohen et al. (1964) measured right-sided systolic pressure gradients in 24 of 29 patients with obstructive cardiomyopathy. Their data show that patients with an indirect mean left atrial pressure of $20 \mathrm{~mm}$. $\mathrm{Hg}$, or above, had virtually no systolic gradient. The largest gradients were in those patients with a low mean left atrial pressure. Thus high pulmonary artery pressures are less likely to be associated with right ventricular systolic gradients. We have failed to show right ventricular systolic pressure gradients in two patients with severe aortic stenosis with pulmonary arterial systolic pressures above 60 $\mathrm{mm}$. Hg. These observations would fit in with the concept of a dynamic gradient which diminishes or disappears if the right ventricular distending pressure is increased. Vogel and Blount (1965) have recently shown that tolazoline in severe pulmonary arterial hypertension in congenital heart disease may unmask right ventricular infundibular obstruction by lowering pulmonary artery pressure and hence infundibular distending pressure.

The cause and site of the systolic pressure gradient in the right ventricle requires further elaboration. Combined discrete congenital aortic and pulmonary stenosis is a rare lesion. Nadas et al. (1962) described four such patients, and Braunwald et al. (1963), in their series of 100 patients with congenital aortic stenosis, found two with associated pulmonary valve stenosis. Other authors have reported single cases (Beard, Cooley, and Latson, 1957; Horlick and Merriman, 1957; Thomas, 1958; Watson, 1963; Kelly, 1965). The lesions can be valvar, subvalvar, or supravalvar, and may be at different levels on the two sides. Discrete anatomical pulmonary obstruction was excluded in all the patients in our series by the catheter, angiographic, and operative findings.

The level of obstruction in the right ventricle in obstructive cardiomyopathy has been placed in the outflow tract by some authors (Braunwald et al., 1964; Mason et al., 1965). However, Taylor et al. (1964), Cohen et al. (1964), and Lockhart et al. 


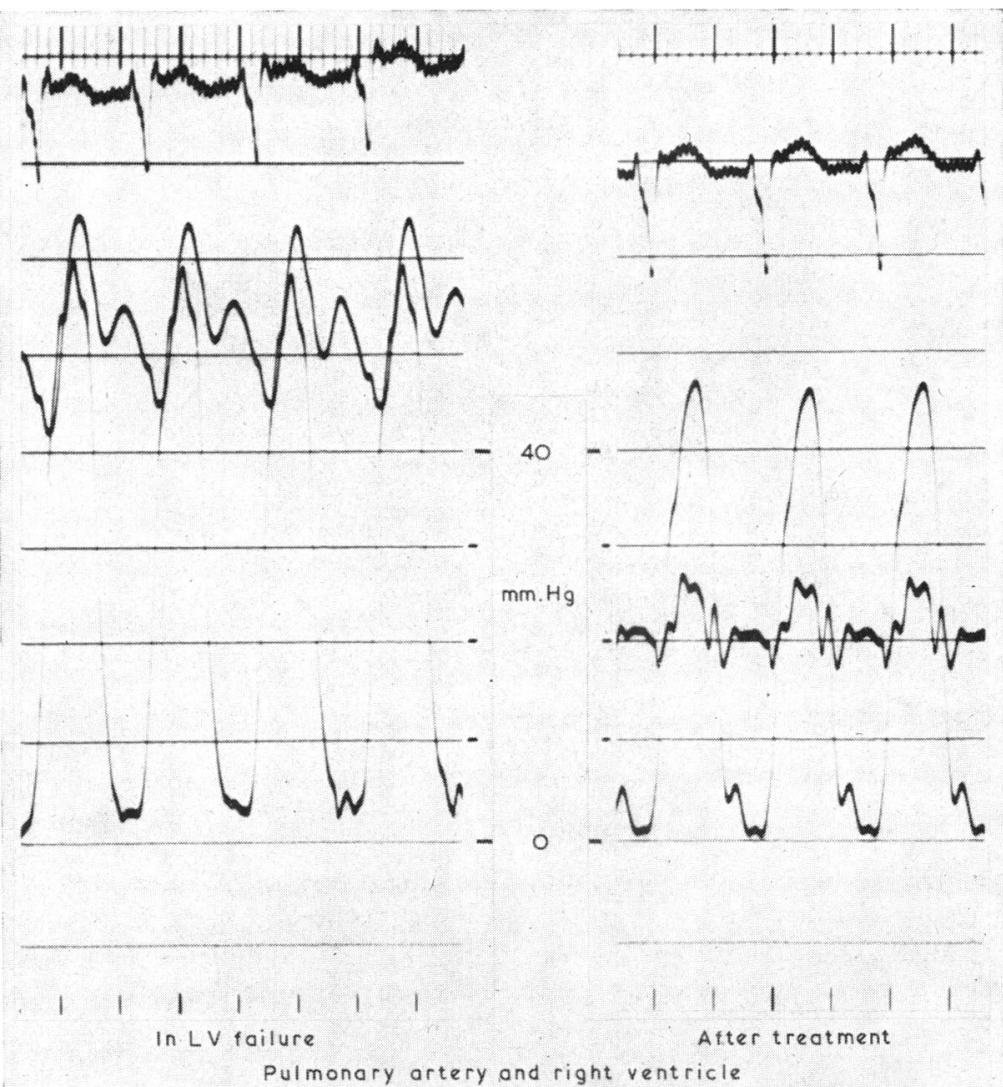

FIG. 9.-Patient No. 14 (E.W.). Severe aortic incompetence. Simultaneous pressure records from the right ventricle and pulmonary artery. The left hand tracings recorded during acute left ventricular failure show an RV systolic pressure of $60 \mathrm{~mm}$. $\mathrm{Hg}$, and a PA systolic pressure of $65 \mathrm{~mm}$. $\mathrm{Hg}$, with a mean left atrial pressure of $21 \mathrm{~mm}$. Hg. The right hand tracings were recorded 30 minutes later after treatment, when mean left atrial pressure had fallen to $7 \mathrm{~mm}$. Hg. The RV systolic pressure was then $47 \mathrm{~mm}$., the PA systolic pressure $27 \mathrm{~mm}$. $\mathrm{Hg}$, and a systolic gradient of $20 \mathrm{~mm}$. $\mathrm{Hg}$ had developed. The PA now showed a bifid systolic wave form.

(1966) have shown that the systolic pressure gradient may be located between the apex and body of the right ventricle rather than in the outflow tract. We have tried to find an anatomical basis for the obstruction in the patients reported here by analysing the right ventricular biplane angiograms in six of these patients. These films closely resemble the right-sided angiograms seen in patients with cardiomyopathy. There is bulging of the interventricular septum into the right ventricle, with displacement and rotation of the right ventricular cavity to the right. In addition, there is marked compression of the cavity with increased trabeculation, and the right ventricular outflow is narrowed due to hypertrophy of the septal and parietal bands of the crista supraventricularis (Fig. 8). However, the gradients that have been demonstrated are not situated at this level but are lower down between the apex and mid-cavity of the right ventricle. Furthermore, there was no correlation between the degree of narrowing of the outflow tract and the systolic gradient. To demonstrate the gradient, it is essential to position carefully the ventricular catheter low down in the right ventricular cavity.

Criley et al. (1965) showed that pressure gradients might develop in the left ventricle in patients with cardiomyopathy without any outflow obstruction demonstrable by angiography. They postulated that the apparent gradients might be due to continuing contraction in areas of the ventricle after complete emptying in early systole. The catheter recorded high pressures in areas of systolic obliteration of the cavity, even though it was lying free in the cavity during diastole. Systolic pressure gradients have also been induced in normal animals by causing excessive systolic emptying of the left 


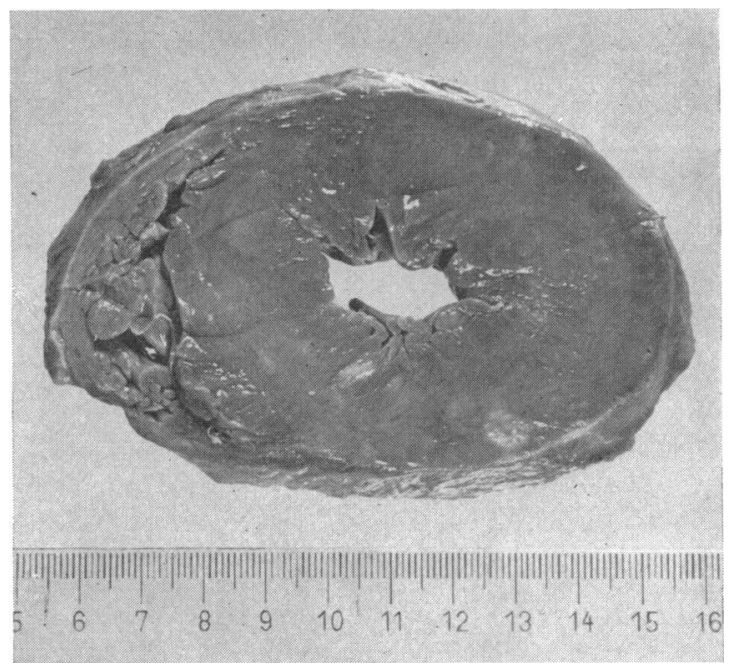

FIG. 10.-Necropsy specimen from a patient with severe aortic stenosis and incompetence not included in this series. Heart weight $850 \mathrm{~g}$. Cross-section at mid-cavity of the ventricles. There is massive concentric left ventricular hypertrophy, and the right ventricular cavity is very compressed from bulging of the hypertrophied ventricular septum. (Scale in centimetres.)

ventricle (Cross and Salisbury, 1963; De Bono, Proctor, and Brock, 1965).

We have been unable to show the presence of any localized obstruction between the apex and body of the right ventricle on the angiograms, and cavity obliteration from septal bulging might explain the systolic pressure gradients that we have observed. Four of the six patients with angiograms showed complete systolic emptying of the apex of the right ventricle. The photograph of a post-mortem specimen from a patient with severe aortic valve disease shows how the right ventricular cavity is very compressed by the hypertrophied interventricular septum (Fig. 10). It is of interest that Bernheim (1910) suggested this mechanism as a cause of right heart failure in patients with left ventricular disease.

The patients reported here each have an abnormal left ventricle due to aortic valve disease, and it seems reasonable to infer that the right ventricular disorder is secondary to the left-sided disease. If this is so, then left ventricular hypertrophy due to other diseases may also produce right-sided gradients. We have found gradients between the right ventricle and pulmonary artery in three other patients: one with coarctation of the aorta; one with coronary artery disease and left ventricular failure; and one with severe systemic hypertension (Table I: Cases 17, 18, and 19). In all three patients the hæmodynamic responses were similar to those in the patients with aortic valve disease; that is, an increase or no change in the right-sided gradients during the strain of the Valsalva manœuvre and a rise in gradient with deep expiration. Patient No. 19 (I.H.) doubled the right ventricular gradient after inhaling amyl nitrite. These three patients support the view that left ventricular hypertrophy, with bulging of the interventricular septum, is responsible for the systolic pressure gradients in the right ventricle, and that aortic valve disease is only of importance as a cause of the left ventricular hypertrophy.

Our results show that the right-sided gradients are dynamic and can be manipulated physiologically and pharmacologically. Thus, left ventricular hypertrophy can produce right-sided gradients of a dynamic nature without invoking a primary disorder of cardiac muscle. It is possible that the right-sided gradients in obstructive cardiomyopathy are also secondary to the septal and left ventricular hypertrophy and not necessarily due to involvement of the right ventricle by the cardiomyopathy. Conversely, the presence of a rightsided dynamic gradient does not exclude fixed orifice obstruction on the left side. Patient No. 5 (L.R.) illustrated this point in that the clinical findings and the cine-angiocardiogram suggested that there was a subvalvar obstruction on the left side. However, the left-sided Valsalva manœuvre showed a typical fixed orifice response. The rightsided catheter studies showed a dynamic right-sided systolic gradient and suggested a cardiomyopathy. At operation there was an aortic valve stenosis, with subvalvar fibrous thickening which had produced 
the unusual cine-angiographic findings. The rightsided gradient may well have been taken as confirming a cardiomyopathy had we not been aware of this finding in aortic valve stenosis.

Systolic pressure gradients in the right ventricle are a relatively common finding in severe aortic valve disease, and gradients have been present in more than half our patients when we have systematically looked for them. They are best demonstrated by simultaneous records of right ventricular and pulmonary artery pressures using two catheters.

We have not found or provoked right ventricular systolic gradients in patients with mitral valve disease, with or without pulmonary hypertension; in pulmonary hypertension due to pulmonary circulatory disorders; or in atrial septal defect.

It is of interest that 7 of the 16 patients had a right ventricular end-diastolic pressure of $7 \mathrm{~mm}$. $\mathrm{Hg}$, or above, in association with a raised mean right atrial pressure and prominent jugular " $a$ " waves in the venous pulse. There was, therefore, resistance to diastolic filling of the right ventricle. Tall jugular "a" waves in patients with aortic valve disease suggest the possibility of a right ventricular systolic pressure gradient.

The dynamic changes induced by various manipulations show that "normal" cardiac muscle can behave in this fashion, and that there is no need to postulate an abnormality of the contractile process to explain the right-sided pressure gradients in obstructive cardiomyopathy.

\section{SUMMARY}

A series of patients with severe aortic valve disease has been found to have systolic pressure gradients between the right ventricle and the pulmonary artery. The site of obstruction was apparently between the apex and the body of the right ventricle.

The pressure gradients were shown to behave dynamically and in a similar fashion to the gradients in obstructive cardiomyopathy, in that they could be manipulated physiologically and pharmacologically. The Valsalva manœuvre generally produced an increase in the gradient during the straining period and so did deep expiration. Amyl nitrite also increased the gradient in the two patients studied. The gradient increased in one patient following isoprenaline but was unchanged in a second patient. Another patient developed a gradient when the pulmonary artery pressure was lowered following treatment of acute left ventricular failure.

Those patients with aortic stenosis showed a fixed orifice type of Valsalva response on the left side, with a considerable fall in the systolic gradient during the straining period.
Cardio-angiography in six patients showed no localized obstruction in the cavity of the right ventricle, though it was compressed by bulging of the hypertrophied ventricular septum. The angiographic findings were similar to those in patients with right-sided gradients in obstructive cardiomyopathy.

Three patients with left ventricular hypertrophy due, respectively, to coarctation of the aorta, coronary artery disease, and severe hypertension showed dynamic right-sided gradients similar to those in patients with aortic valve disease.

These findings support the view that the systolic pressure gradients in the right ventricle are secondary to left ventricular hypertrophy with bulging of the ventricular septum into the right ventricular cavity. Aortic valve disease may only be of importance as a cause of left ventricular hypertrophy.

Right-sided gradients in hypertrophic obstructive cardiomyopathy may also be secondary to the left ventricular disorder and not necessarily due to involvement of the right ventricle by the cardiomyopathy.

If a right-sided gradient is dynamic, it does not necessarily follow that an associated left ventricular outflow obstruction is due to cardiomyopathy.

The authors are grateful to Sister J. Davies, in charge of the Catheter Laboratory, and to Mrs. B. Lea, Senior Cardiographic Technician, and their respective staffs for invaluable technical assistance.

\section{REFERENCES}

Beard, E. F., Cooley, D. A., and Latson, J. R. (1957). Combined congenital subaortic stenosis and infundibular subpulmonic stenosis. Arch. intern. Med., 100, 647.

Beck, W., Schrire, V., Vogelpoel, L., Nellen, M., and Swanepoel, A. (1961). Hemodynamic effects of amyl nitrite and phenylephrine on the normal human circulation and their relation to changes in cardiac murmurs. Amer. F. Cardiol., 8, 341.

Bernheim, P. I. (1910). De l'asystolie veineuse dans l'hypertrophie du coeur gauche par sténose concomitante du ventricule droit. Rev. Méd. (Paris), 30, 785.

Braunwald, E., and Ebert, P. A. (1962). Hemodynamic alterations in idiopathic hypertrophic subaortic stenosis induced by sympathomimetic drugs. Amer.F. Cardiol., $10,489$.

—, Goldblatt, A., Aygen, M. M., Rockoff, S. D., and Morrow, A. G. (1963). Congenital aortic stenosis I: Clinical and hemodynamic findings in 100 patients. Circulation, 27, 426.

—, Lambrew, C. T., Rockoff, S. D., Ross, J., and Morrow, A. G. (1964). Idiopathic hypertrophic subaortic stenosis: I. A description of the disease based upon an analysis of 64 patients. Circulation, 30, Suppl. IV.

—, Morrow, A. G., Cornell, W. O., Aygen, M. M., and Hilbish, T. F. (1960). Idiopathic hypertrophic subaortic stenosis: Clinical, hemodynamic and angiographic manifestations. Amer. F. Med., 29, 924. 
Brent, L. B., Aburano, A., Fisher, D. L., Moran, T. J., Myers, J. D., and Taylor, W. J. (1960). Familial muscular subaortic stenosis: An unrecognized form of "idjopathic heart disease", with clinical and autopsy observations. Circulation, 21, 167.

Brock, R. (1955). Control mechanisms in the outflow tract of the right ventricle in health and disease. Guy's Hosp. Rep., 104, 356.

- (1957). Functional obstruction of the left ventricle (acquired aortic subvalvar stenosis). Guy's Hosp. Rep., 106, 221.

Brockenbrough, E. C., Braunwald, E., and Morrow, A. G. (1961). A hemodynamic technic for the detection of hypertrophic subaortic stenosis. Circulation, 23, 189.

Cohen, J., Effat, H., Goodwin, J. F., Oakley, C. M., and Steiner, R. E. (1964). Hypertrophic obstructive cardiomyopathy. Brit. Heart f., 26, 16.

Criley, J. M., Lewis, K. B., White, R. I., and Ross, R. S. (1965). Pressure gradients without obstruction. A new concept of "hypertrophic subaortic stenosis". Circulation, 32, 881.

Cross, C. E., and Salisbury, P. F. (1963). Functional subaortic stenosis produced in animals. Amer. F. Cardiol., $12,394$.

De Bono, A. H., Proctor, E., and Brock, R. (1965). Dynamic obstruction of the left ventricle: Its production and abolition by drugs in normal animals. Guy's Hosp. Rep., $114,4$.

Goodwin, J. F., Hollman, A., Cleland, W. P., and Teare, D. (1960). Obstructive cardiomyopathy simulating aortic stenosis. Brit. Heart f., 22, 403.

—, Shah, P. M., Oakley, C. M., Cohen, J., Yipintsoi, T., and Pocock, W. (1964). The clinical pharmacology of hypertrophic obstructive cardiomyopathy. In Cardiomyopathies: A Ciba Foundation Symposium, ed. G. E. W. Wolstenhome and M. O'Connor, p. 189. J. and A. Churchill, London.

Gorlin, R., and Gorlin, S. G. (1951). Hydraulic formula for calculation of the area of the stenotic mitral valve, other cardiac valves, and central circulatory shunts. Amer. Heart f., 41, 1.

Hancock, E. W., and Fowkes, W. C. (1966). Effects of amyl nitrite in aortic valvular and muscular subaortic stenosis. Circulation, 33, 383.

Horlick, L., and Merriman, J. E. (1957). Congenital valvular stenosis of pulmonary and aortic valves with atrial septal defect. Amer. Heart $\mathcal{F}$., 54, 4.

Kelly, D. T. (1965). Congenital stenosis of pulmonary and aortic valves. Amer. F. Cardiol., 16, 750.

Kirklin, J. W., Connolly, D. C., Ellis, F. H., Burchell, H. B., Edwards, J. E., and Wood, E. H. (1953). Problems in the diagnosis and surgical treatment of pulmonic stenosis with intact ventricular septum. Circulation, 8, 849.

Krasnow, N., Rolett, E., Hood, W. B., Yurchak, P. M., and Gorlin, R. (1963). Reversible obstruction of the ventricular outflow tract. Amer. F. Cardiol., 11, 1.

Little, J. B., Lavender, J. P., and DeSanctis, R. W. (1963).
The narrow infundibulum in pulmonary valvular stenosis. Its preoperative diagnosis by angiocardiography. Circulation, 28, 182.

Lockhart, A., Charpentier, A., Bourdarias, J. P., Ben Ismail, M., Ourbak, P., and Scebat, L. (1966). Right ventricular involvement in obstructive cardiomyopathies: hæmodynamic studies in 13 cases. Brit. Heart f., 28, 122.

Marcus, F. I., and Jones, R. C. (1965). The use of the Valsalva maneuver to differentiate fixed-orifice aortic stenosis from muscular subaortic stenosis. Amer. Heart f., 69, 473.

Mason, D. T., Braunwald, E., and Ross, J., Jr. (1965). Hæmodynamic alterations induced by isoprenaline in patients with obstruction to right ventricular outflow. Brit. Heart f., 27, 884.

Nadas, A. S., Van der Hauwaert, L., Hauck, A. J., and Gross, R. E. (1962). Combined aortic and pulmonic stenosis. Circulation, 25, 346.

Oakley, C. M. (1964). Discussion. In Cardiomyopathies: A Ciba Foundation Symposium, ed. G. E. W. Wolstenholme and M. O'Connor, p. 93. J. and A. Churchill, London.

Rodbard, S., and Shaffer, A. B. (1956). Muscular contraction in the infundibular region as a mechanism of pulmonic stenosis in man. Amer. Heart f., 51, 885.

Shah, P. M., Yipintsoi, T., Amarasingham, R., and Oakley, C. M. (1965). Effects of respiration on the hemodynamics of hypertrophic obstructive cardiomyopathy. Amer. F. Cardiol., 15, 793.

Taylor, R. R., Bernstein, L., and Jose, A. D. (1964). Obstructive phenomena in ventricular hypertrophy. Brit. Heart F., 26, 193.

Thomas, A. J. (1958). Congenital stenosis of pulmonary and aortic valves with patent ductus arteriosus. Amer. Heart F., 55, 724.

Vogel, J. H. K., and Blount, S. G. (1965). Masked infundibular pulmonary obstruction in ventricular septal defect with pulmonary hypertension. Circulation, 31, 876.

Watson, G. H. (1963). Supravalvar pulmonary and aortic stenoses coexisting. Brit. Heart f., 25, 817.

Whalen, R. E., Cohen, A. I., Sumner, R. G., and McIntosh, H. D. (1963). Demonstration of the dynamic nature of idiopathic hypertrophic subaortic stenosis. Amer. f. Cardiol., 11, 8.

Wigle, E. D. (1964). Muscular subaortic stenosis: The clinical syndrome, with additional evidence of ventricular septal hypertrophy. In Cardiomyopathies: $A$ Ciba Foundation Symposium, ed. G. E. W. Wolstenhome and M. O'Connor, p. 49. J. and A. Churchill, London.

—, David, P. R., Labrosse, C. J., and McMeekan, J. (1965). Muscular subaortic stenosis. The interrelation of wall tension, outflow tract "distending pressure" and orifice radius. Amer. f. Cardiol., 15, 761.

—, Lenkei, S. C. M., Chrysohou, A., and Wilson, D. R. (1963). Muscular subaortic stenosis: The effect of peripheral vasodilatation. Canad. med. Ass. F., 89, 896. 